\title{
Sources of Resistance in U.S. Plant Introductions to Watermelon Vine Decline Caused by Squash Vein Yellowing Virus
}

\author{
Chandrasekar S. Kousik ${ }^{1}$ \\ U.S. Department of Agriculture-Agriculture Research Service, U.S. \\ Vegetable Laboratory, 2700 Savannah Highway, Charleston, SC 29414
}

Scott Adkins and William W. Turechek

U.S. Department of Agriculture-Agriculture Research Service, U.S. Horticultural Research Laboratory, Ft. Pierce, FL 34945

\section{Pamela D. Roberts \\ Southwest Florida Research and Education Center, University of Florida, Immokalee, FL 34142}

Additional index words. Bemisia tabaci, Potyvirus, Cucurbit, Ipomovirus, host plant resistance

\begin{abstract}
Watermelon vine decline (WVD) is a new and emerging disease caused by the whitefly-transmitted squash vein yellowing virus ( $\mathrm{SqVYV})$. The disease has become a major limiting factor in watermelon [Citrullus lanatus (Thunb.) Matsum. \& Nakai] production in southwest and west-central Florida and is estimated to have caused more than \$60 million in losses. Symptoms of WVD typically occur at or just before harvest and are manifested as sudden decline of the vines, often with a reduction in fruit quality. In this study, we present results of greenhouse and field evaluations of U.S. plant introductions (PIs) for resistance to SqVYV. Of the 218 PIs we evaluated for resistance to $\mathrm{SqVYV}$, none were completely immune, but several showed varying levels of resistance and these were further evaluated in two greenhouse and field trials. Disease progress was significantly slower on the selected PIs compared with disease progress on susceptible watermelon cultivars Mickey Lee and Crimson Sweet. Moderate resistance was observed in two C. colocynthis (PI 386015 and PI 386024), a Praecitrullus fistulosus (PI 381749), and two C. lanatus var. lanatus PIs (PI 482266 and PI 392291). Variability in the resistant reaction to $\mathrm{SqVYV}$ within most PIs was observed. The identification of potential sources of partial resistance to SqVYV suggests that watermelon germplasm with moderate resistance can be developed by careful screening and selection of individual resistant plants within these PIs for use in breeding programs.
\end{abstract}

Watermelon vine decline (WVD) caused by squash vein yellowing virus (SqVYV) is a new and emerging disease that has caused devastating losses for watermelon producers in southwest and west-central Florida (Huber, 2006; Roberts et al., 2005). Monetary losses resulting from WVD in Florida were estimated at $\$ 60$ to $\$ 70$ million in 2004 (Huber, 2006). Symptoms of WVD typically occur at or just before harvest, when vines collapse rapidly (Adkins et al., 2007; Huber, 2006; Roberts et al., 2005). Although exter-

\footnotetext{
Received for publication 1 Oct. 2008. Accepted for publication 30 Nov. 2008

We acknowledge the technical assistance of William Cook, Jessie Dufault, Richard Carrington Dunn, Rod Sytsma, and Carrie Vanderspool in conducting the greenhouse and field experiments. Mention of a trademark name or proprietary product does not constitute a warranty or guarantee by the U.S. Department of Agriculture nor does it imply exclusion of other products that may also be suitable. ${ }^{1}$ To whom reprint requests should be addressed; e-mail shaker.kousik@ars.usda.gov.
}

nally the fruits appear normal, rind necrosis and flesh degradation are often evident when fruits are cut, affecting marketability of the fruits (Adkins et al., 2007; Huber 2006; Roberts et al., 2005). Recent research identified the novel SqVYV (genus: Ipomovirus, family: Potyviridae) as the causal agent of WVD (Adkins et al., 2007, 2008). SqVYV is transmitted by whiteflies (Bemisia tabaci, Biotype B) and is also mechanically transmitted (Adkins et al., 2007). Currently, the known host range of SqVYV is limited to cucurbits, including several cucurbit weeds (Adkins et al., 2007, 2008) with the most striking symptoms of vine collapse (WVD) seen only in watermelon (Adkins et al., 2007). SqVYV is now widely distributed in cucurbits in southwest and west-central Florida (Adkins et al., 2007, 2008) and it was recently identified in Indiana (Egel and Adkins, 2007) and South Carolina (Kousik and Adkins, unpublished data). WVD has become endemic in Florida and has appeared to varying degrees every season since it was first observed. Watermelons infected with SqVYV are also frequently infected with the aphid-transmitted papaya ringspot virus type W (PRSV-W), although SqVYV is sufficient to cause WVD (Adkins et al., 2007).

Current management strategies for WVD and SqVYV in Florida include destruction of cucurbit weed hosts, cucurbit volunteer plants, and the management of whiteflies by insecticide application and use of silver plastic mulch (Adkins et al., 2008; Kousik et al., 2008). However, the complete destruction of virus reservoirs is difficult in practice and in recent years there has been a marked increase of insecticide resistant whitefly populations in Florida, particularly to neonicotinoids (Schuster et al., 2006). Moreover, the emergence of Biotype Q whitefly populations resistant to many of the commonly used insecticides in nurseries and greenhouse production is a matter of great concern to growers in most states, including Florida (Dennehy et al., 2005; Schuster et al., 2007). At present, it is not known if the Biotype Q whitefly can transmit SqVYV.

Thus, the search for long-term and sustainable strategies to manage SqVYV remains important. Development of watermelon cultivars resistant to either SqVYV or its whitefly vector is a promising alternative. Partial resistance to cucumber vein yellowing virus (CVYV), a SqVYV relative found in the Mediterranean region (Al-Musa et al., 1985; Cuadrado et al., 2001; Yilmaz et al., 1989), has been identified in wild relatives of cucumbers (Pico et al., 2003, 2005) and melon (Marco et al., 2003). Similarly, resistance or tolerance to aphid-transmitted members of the family Potyviridae, including PRSV-W, watermelon mosaic virus (WMV), and Zucchini yellow mosaic virus (ZYMV), have been identified in watermelon (Boyhan et al., 1992; Gillaspie and Wright, 1993; Strange et al., 2002; Xu et al., 2004). Therefore, it is likely that resistance to SqVYV can be found in wild relatives of the cultivated watermelon. In this article, we present results of greenhouse and field evaluation of the watermelon core collection of U.S. plant introductions (PIs) for resistance to SqVYV. Parts of this study have been previously reported (Kousik et al., 2007a, 2007b).

\section{Materials and Methods}

Virus source. The original squash isolate of SqVYV isolated from Hillsborough County, FL (Adkins et al., 2007, 2008) was maintained in squash (Cucurbita pepo) cv. Prelude II (Seminis Seeds, Oxnard, CA) plants by mechanical inoculation in a greenhouse using $20 \mathrm{~mm}$ sodium phosphate buffer ( $\mathrm{pH} 7.0)$ containing $0.1 \%(\mathrm{wt} / \mathrm{vol})$ sodium sulfite and $1 \%$ (wt/vol) celite as previously described by Adkins et al. (2007, 2008). Mechanical inoculations were performed by gently rubbing the inoculum on the cotyledons and the first true leaves of 3- to 4-week-old plants using a cheesecloth.

Seed sources. Seeds of PIs of the watermelon core collection were obtained from the USDA, ARS, Plant Genetic Resources and Conservation Unit (PGRCU), Griffin, GA. 
The details of the PI in the core collection can be obtained from the Germplasm Resources Information Network (GRIN) online database at http://www.ars-grin.gov. Seed of PI 386024 , which is not part of the core collection, was also included in these studies because of its reported resistance to whiteflies (Simmons and Levi, 2002) and were also obtained from PGRCU. Seeds of the openpollinated susceptible controls 'Mickey Lee' and 'Crimson Sweet' were obtained from Willhite Seed Inc. (Poolville, TX).

Evaluation of the watermelon core collection. Seeds of the entire core collection consisting of 253 PIs were planted in 90$\mathrm{mm}$ square pots filled with Metro Mix 360 (Sun Gro Horticulture, Seba Beach, Alberta, Canada) and seedlings were grown in an airconditioned greenhouse in Fort Pierce, FL, under natural lighting with a daytime high temperature of $30^{\circ} \mathrm{C}$ in 2006 . Four single plant replications were used for each PI and eight plants for the controls. The cotyledons and the first true leaf of all plants (generally 3 to 4 weeks old) were mechanically inoculated with SqVYV-infected squash leaves homogenized in the phosphate-sulfite buffer as described previously. Only 218 PIs could be evaluated because of low or no germination for some of the PIs in the core collection. Plants were monitored for symptom appearance on a weekly basis and were rated on a 1 to 9 ordinal scale based on the extent of plant foliage affected and severity of symptoms as indicated: $1=$ no symptoms; $2=$ very minor chlorosis/vein yellowing, no necrosis; 3 = minor chlorosis/vein yellowing plus mild epinasty of youngest upper leaves; $4=$ chlorosis/vein yellowing plus severe epinasty of youngest upper leaves, no necrosis; $5=$ chlorosis of most basal leaves, necrotic streaks in petioles and/or tendrils; $6=$ necrosis of most basal

Table 1. Response of plant introductions (PIs) in the watermelon core collection to squash vein yellowing virus inoculation in a greenhouse in Ft. Pierce, FL.

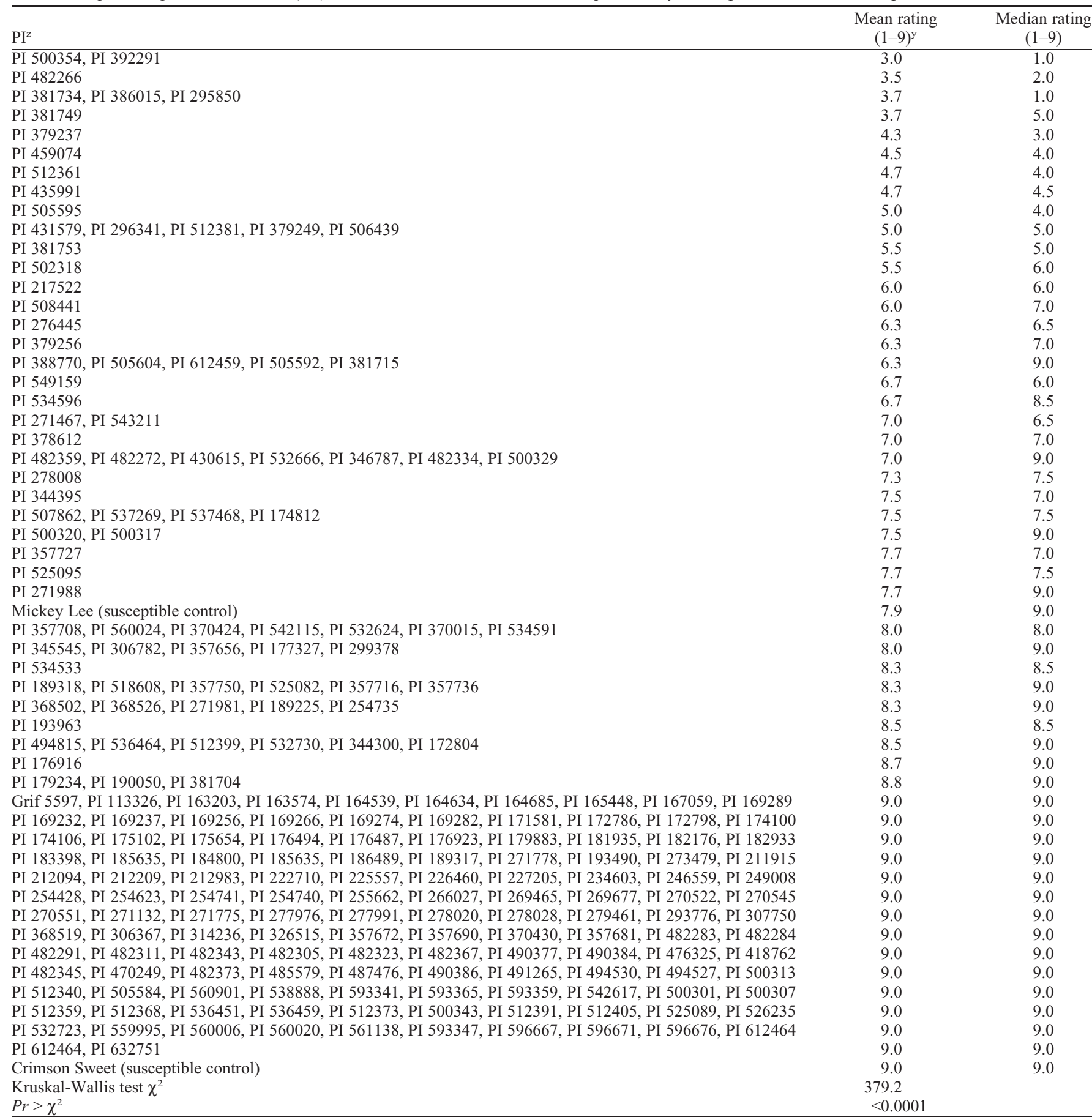

${ }^{2}$ Details of individual PIs can be obtained from GRIN (http://www.ars-grin.gov).

${ }^{y}$ Final rating recorded 8 weeks after inoculation. Details of the 1 to 9 rating scale is provided in the text. 
leaves, petiole collapse; $7=$ necrosis of most leaves, total petiole collapse, main stem mostly green/yellow; $8=$ necrosis of most leaves, stem necrosis and slight collapse, stem tip dead; and 9 = plant dying or dead. Plants within PIs that were not dead after 4 weeks from the time of first inoculation were inoculated a second time to ensure that they were not escapes. Most plants were rated four times. The last ratings were recorded 8 weeks after the first inoculation.

Greenhouse evaluation of select PIs. The most resistant PIs with a mean rating less than 4.5 identified in the 2006 evaluation of the core collection were further evaluated in two greenhouse trials in Fort Pierce, FL, in Spring 2007. In the first greenhouse trial, nine PIs (PI 381749, PI 386015, PI 386024, PI 482266, PI 392291, PI 459074, PI 381734, PI 500354, and PI 295850) were evaluated with 10 single plant replicates. In the second trial, six of the nine PIs (PI 381749, PI 386015, PI 386024, PI 482266, PI 392291, and PI 500354) from the previous trial were evaluated with 20 single plant replicates. The susceptible cultivar Mickey Lee was included as a control in both the trials and 'Crimson sweet' served as an additional control in the first trial. PI 386024 , which is not part of the core collection, was also included in both of these studies. Plants for both trials were grown in 90-mm square pots filled with Metro Mix 360 and mechanically inoculated as described previously. All the plants were treated with the insecticide imidacloprid (Admire Pro; Bayer Crop Science, Research Triangle Park, $\mathrm{NC)}$ to prevent whitefly and aphid infestations. Plants were rated twice weekly on the 1 to -9 scale described previously to monitor disease progress for 4 weeks after inoculation in the first trial and for 5 weeks after inoculation in the second trial.

Field evaluation. The most resistant PIs with a mean rating less than 4.5 in the 2006 screening of the core collection were also evaluated in field trials at the Southwest Florida Research and Education Center in Immokalee, FL, in the fall of 2006 and 2007. In 2006, 4-week-old plants of nine PIs (PI 386015, PI 386024, PI 482266, PI 392291, PI 381734, PI 244018, PI 299378, PI 500354, and PI 295850) and susceptible controls grown in 50-cell Jiffy trays were transplanted onto raised beds fumigated with Telone C-35 applied in-bed at $327 \mathrm{~L} \cdot \mathrm{ha}^{-1} 2$ weeks before transplanting on 12 Sept. Beds were $0.81 \mathrm{~m}$ wide with $3.7-\mathrm{m}$ centers covered with white plastic mulch. The experimental design was a randomized complete block with three replications. Individual plots consisted of five plants spaced $61 \mathrm{~cm}$ apart. A 4-week-old SqVYV-infected squash plant (mechanically inoculated as described previously) was planted at the end of each plot and served as the initial source of inoculum. In fall of 2007, transplants of seven PIs (PI 386015, PI 386024, PI 482266, PI 392291, PI 459074, PI 381734, and PI 500354), the susceptible controls, and the field were prepared similarly as in 2006. Seedlings were transplanted on 11 Sept. The experimental design was a randomized complete block with four replications and each plot contained 10 plants spaced $46 \mathrm{~cm}$ apart. In both years, guidelines established by the University of Florida/IFAS were followed for land preparation, fertility, irrigation, and weed management (Olson et al., 2007). No chemicals were applied for whitefly management.

Plants were monitored for SqVYV symptom appearance on a regular basis. Symptoms were rated on the same 1 to 9 ordinal scale used in the greenhouse experiments. Disease ratings were recorded on 31 Oct., 20 Nov., and 4 Dec. in 2006 and on 27 Sept., 4 Oct., 18 Oct., 27 Nov., and 10 Dec. in 2007. Additionally, all the fruits were cut and examined for WVD symptoms on 10 Dec. 2007. Data on total fruit and number of symptomatic fruit were recorded.

Statistical analysis. The rating scale data from evaluation of the core collection were analyzed by using the Kruskal-Wallis test with the SAS procedure PROC NPAR1WAY (Version 8.0; SAS Institute, Cary, NC). The greenhouse and field ratings collected over time for each PI were analyzed as repeated measures data using the nonparametric analysis described by Shah and Madden (2004) and Brunner et al. (2002). To perform the analysis, the SAS macro F1_LD_F1 was used to determine the effect of PI, time, and its interaction on the severity of SqVYV, and the SAS macro LD_CI was used to obtain estimates of the relative effects and their confidence intervals. Both macros can be downloaded for free from the web site of $\mathrm{E}$. Brunner at the University of Göttingen, Germany (http://www.ams.med.uni-goettingen. $\mathrm{de} / \mathrm{de} / \mathrm{sof} / \mathrm{ld} / \mathrm{makros} . h \mathrm{tml})$. In short, the relative effect for the $i$ th treatment, $p_{i}$, describes the stochastic tendency of the normalized distribution $F_{i}(x)$ for the random variable $X_{i}$ relative to the weighted average of all the $F_{i}(x) \mathrm{s}$ in the experiment. An estimate of the relative treatment effect can be obtained from the observed midranks. If $R_{i k}$ is the rank of $X_{i k}$ among all $N$ observations, the mean rank for the $i$ th treatment is estimated by $\bar{R}_{i \bullet}=$

Table 2. Mean squash vein yellowing virus (SqVYV) rating (1 to 9), country, Citrullus group, median, mean rank, and Z statistic for select U.S. plant introductions (PIs) from the watermelon core collection evaluated in a greenhouse in Fort Pierce, FL.

\begin{tabular}{llcccrc}
\hline PI & \multicolumn{1}{c}{ Country $^{z}$} & $\begin{array}{c}\text { Citrullus } \\
\text { group }^{\mathrm{y}}\end{array}$ & $\begin{array}{c}\text { Mean SqVYV } \\
\text { rating (1-9) }\end{array}$ & $\begin{array}{c}\text { Median rating } \\
(1-9)\end{array}$ & Mean rank $^{\mathrm{w}}$ & $Z^{v}$ \\
\hline PI 381749 & India & P & 3.7 & 5.0 & 53.3 & -2.62 \\
PI 386015 & Iran & CO & 3.7 & 1.0 & 177.7 & -1.70 \\
PI 482266 & Zimbabwe & CLL & 3.5 & 2.0 & 145.9 & -2.24 \\
PI 392291 & Kenya & CLL & 3.0 & 1.0 & 139.0 & -2.30 \\
PI 459074 & Botswana & CLL & 4.5 & 4.0 & 157.3 & -2.14 \\
PI 381734 & India & CLL & 3.7 & 1.0 & 177.7 & -1.70 \\
PI 295850 & South Africa & CLC & 3.7 & 1.0 & 177.7 & -1.70 \\
PI 500354 & Zambia & CLC & 3.0 & 1.0 & 139.0 & -2.30 \\
Crimson Sweet & USA & CL & 9.0 & 9.0 & 487.0 & +0.98 \\
Mickey Lee & USA & CL & 7.9 & 9.0 & 420.7 & +0.12 \\
\hline
\end{tabular}

${ }^{\mathrm{z}}$ Country from which the PI was originally collected.

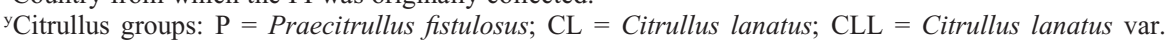
lanatus; $\mathrm{CLC}=$ Citrullus lanatus var. citroides; $\mathrm{CO}=$ Citrullus colocynthis.

${ }^{\mathrm{x}}$ Mean and median rating for this table is the same as in Table 1 and is based on data recorded for four replications for each PI on the 1 to 9 scale.

${ }^{w}$ Mean rank was calculated using the nonparametric PROC NPAR1WAY procedure of SAS.

${ }^{v}$ All PIs with negative $Z$ scores in this table had significantly less disease compared with the controls that had positive $Z$ scores. 
Table 3. Test statistics for the effects of select U.S. plant introductions (PIs) and time on the severity of squash vein yellowing virus infection in two greenhouse trials conducted in 2007.

\begin{tabular}{lccrc}
\hline & \multicolumn{4}{c}{ Analysis of variance-type statistic } \\
\cline { 2 - 5 } Effect & $d f_{N}$ & $d f_{D}$ & \multicolumn{1}{c}{$F$} & $P$ value \\
\hline Greenhouse & Trial 1 $1^{y}$ & & & \\
PI & 4.24 & 39.43 & 16.57 & $<0.00001$ \\
Time (T) & 2.83 & $\infty$ & 757.49 & $<0.00001$ \\
PI $\times$ T & 9.91 & $\infty$ & 5.98 & $<0.00001$ \\
Greenhouse & Trial 2 & & & \\
PI & 5.06 & 104.96 & 30.54 & $<0.00001$ \\
Time (T) & 2.00 & $\infty$ & 794.97 & $<0.00001$ \\
PI $\times$ T & 7.87 & $\infty$ & 8.78 & $<0.00001$ \\
\hline
\end{tabular}

${ }^{2}$ Analysis of variance-type statistic was calculated using nonparametric methods as described by Shah and Madden (2004).

${ }^{\mathrm{y}}$ In the first greenhouse trial, there were 10 replications, and in the second, there were 20 replications for each PI. Plants were rated seven times after inoculation over 4 weeks in the first greenhouse trial and nine times over 5 weeks in the second greenhouse trail.

$d f_{N}=$ numerator df; $d f_{D}=$ denominator $\mathrm{df}$.

SqVYV rating, median rating, and average rank scores for select PIs with average ratings less than 4.5 and the susceptible controls. All these PIs were rated for the 8-week duration after inoculation. These PIs had significantly less disease than the susceptible controls 'Mickey Lee' and 'Crimson Sweet' when the ranks were compared using $\mathrm{Z}$ scores (Table 2).

Greenhouse trials. Two greenhouse trials were conducted to identify the range of response to SqVYV on the select watermelon PI identified from the core collection screen. A highly significant $(P<0.00001)$ interaction between PIs and rating period (time) was observed in both trials (Table 3 ), indicating that disease progression occurred at different rates among the PIs (Fig. 1). The overall effect of SqVYV on the severity of vine decline symptoms on the PIs in the greenhouse evaluation is presented in Table 4. In the first trial, eight PIs had significantly less disease than the controls and all six PIs (PI 381749, PI 386015, PI 386024, PI 482266, PI 392291, and PI 500354) had less disease in the second trial (Table 4). The disease progress on each of these six PIs as relative treatment effect over time is presented in Figure 1. Of the six PIs evaluated in both trials, five had significantly less disease than the susceptible control 'Mickey Lee' throughout the course of the experiments (Fig. 1). In both greenhouse trials, the Praecitrullus fistulosus PI 381749 from India was the most tolerant and had significantly less disease compared with the susceptible controls. Three C. lanatus var. lanatus PIs (PI 482266, PI 392291, and PI 459074) from different regions of Africa had significantly $(P<0.002)$ less disease compared with the susceptible controls in the first trial and of these three PIs, two had significantly less disease in the second trial as well (Table 4). The citron watermelon PI 500354 (C. lanatus var. citroides) from Zambia and the two Citrullus colocynthis desert PIs from Iran had significantly less disease compared with the controls in both trials.
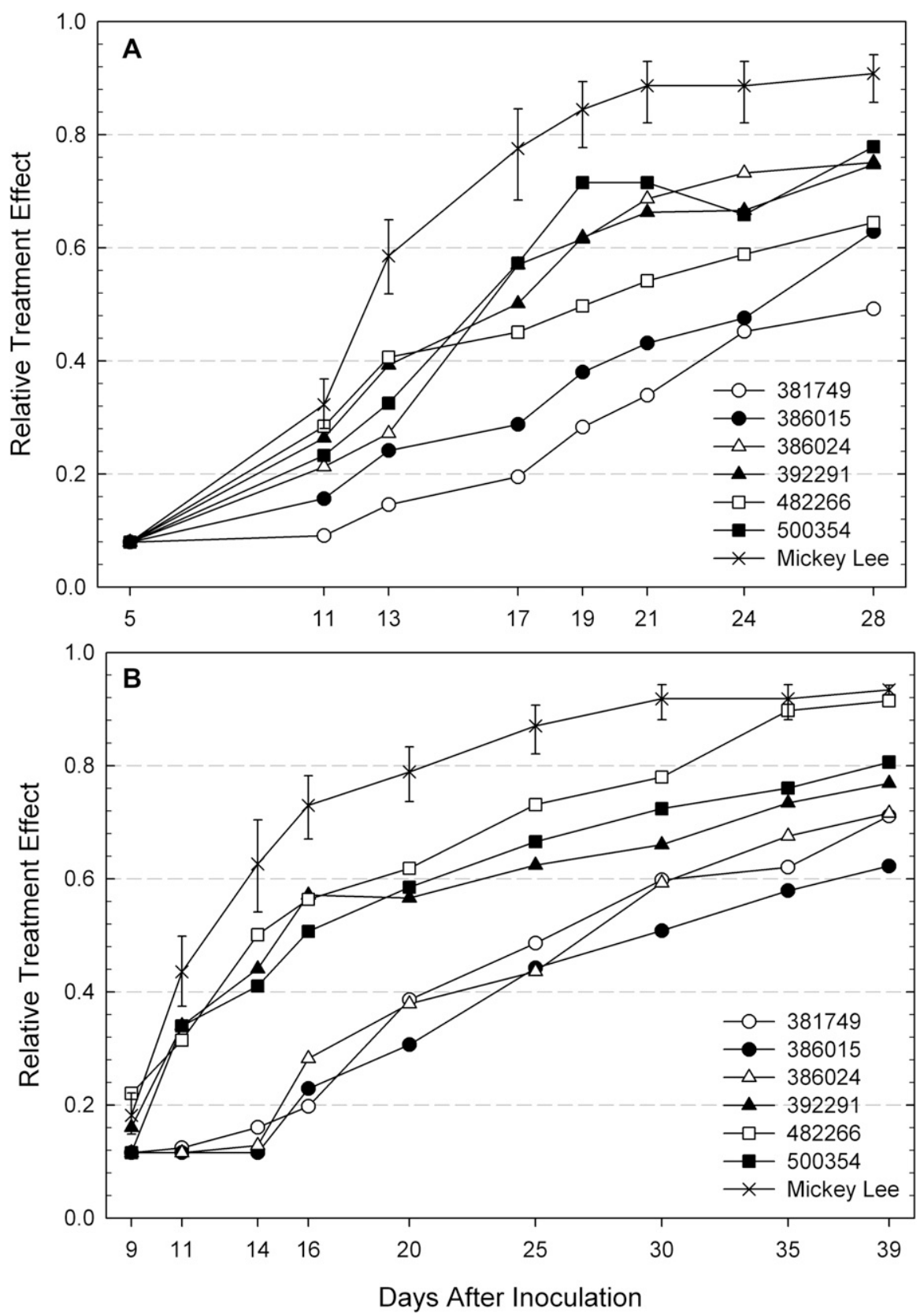

Fig. 1. Relative treatment effect (RTE) of select U.S. PIs on development of watermelon vine decline in (A) greenhouse Trial 1 and (B) greenhouse Trial 2. Plants within each PI were mechanically inoculated with squash vein yellowing virus and disease ratings were recorded on a 1 to 9 scale on a regular basis. The effect of each PI on development of disease is indicated as the relative treatment effect. 'Mickey Lee', a commercial watermelon (Citrullus lanatus) cultivar, was the susceptible control.

Field evaluation. Initial disease spread during both field seasons began on the plants closest to the previously inoculated and symptomatic squash plant. The ATS indicated that significant $(P<0.008)$ differences in disease development existed among the PIs in both years (Table 5). A significant ( $P=$ $0.009)$ interaction between PI $\times \mathrm{T}$ was also observed in 2006 further indicating the variability in disease development among the various PIs over time. In 2007, the interaction of PI $\times$ T was at $P=0.057$ (Table 5). During both the years, the susceptible controls of 'Mickey Lee' and 'Crimson Sweet' were severely diseased early in the season and disease progressed very rapidly on these two cultivars compared with the PIs. Overall, PI 500354 (C. lanatus var. citroides) was the most tolerant in 2006 (Table 6); however, plants within this PI also succumbed to WVD. Interestingly, PI 500354 that was the most tolerant in 2006 was severely diseased in 2007 (Table 7) and not significantly different from the controls. The two Citrullus colocynthis desert watermelon PIs from Iran (PI 386015 and PI 386024) had significantly less disease compared with the controls in both years (Tables 6 and 7). Three Citrullus lanatus var. lanatus PIs from southern regions of Africa (PI 482266, PI 381734, and PI 392291) and another C. lanatus var. citroides, PI 299378, had significantly less 
Table 4. Mean rank, and relative treatment effect (RTE) for the effects of select U.S. plant introductions (PIs) on the severity of squash vein yellowing virus infection in two greenhouse trials $\left(\begin{array}{lll}1 & \text { and } & 2\end{array}\right)$ conducted in Fort Pierce, FL, Spring 2007.

\begin{tabular}{|c|c|c|c|c|c|c|c|}
\hline \multirow[b]{2}{*}{ PI } & \multirow[b]{2}{*}{ Country $^{z}$} & \multirow{2}{*}{$\begin{array}{l}\text { Citrullus } \\
\text { group }^{\mathrm{y}}\end{array}$} & \multicolumn{2}{|c|}{ Greenhouse Trial $1^{x}$} & \multicolumn{2}{|c|}{ Greenhouse Trial $2^{w}$} & \multirow{2}{*}{$\begin{array}{c}\text { Plants rated } \\
\text { less than } 5(\%)^{v}\end{array}$} \\
\hline & & & Mean rank & RTE & Mean rank & RTE & \\
\hline$\overline{\text { PI } 381749}$ & India & $\mathrm{P}$ & $229.0 \mathrm{a}$ & 0.260 & $459.3 \mathrm{a}$ & 0.337 & 53 \\
\hline PI 386015 & Iran & $\mathrm{CO}$ & $295.3 \mathrm{a}$ & 0.335 & $410.1 \mathrm{a}$ & 0.337 & 54 \\
\hline PI 386024 & Iran & $\mathrm{CO}$ & $431.7 \mathrm{bc}$ & 0.490 & $465.0 \mathrm{a}$ & 0.382 & 33 \\
\hline PI 482266 & Zimbabwe & CLL & $384.7 \mathrm{~b}$ & 0.437 & $748.6 \mathrm{c}$ & 0.616 & 10 \\
\hline PI 392291 & Kenya & CLL & $433.0 \mathrm{bc}$ & 0.492 & $657.3 \mathrm{~b}$ & 0.541 & 32 \\
\hline PI 459074 & Botswana & CLL & $443.2 \mathrm{c}$ & 0.503 & - & - & - \\
\hline PI 381734 & India & CLL & $502.6 \mathrm{~cd}$ & 0.571 & - & - & 一 \\
\hline PI 295850 & South Africa & CLC & $543.6 \mathrm{de}$ & 0.617 & - & - & - \\
\hline PI 500354 & Zambia & CLC & $449.0 \mathrm{c}$ & 0.510 & $663.8 \mathrm{bc}$ & 0.546 & 22 \\
\hline Crimson Sweet & USA & $\mathrm{CL}$ & $551.1 \mathrm{e}$ & 0.626 & - & - & 一 \\
\hline Mickey Lee & USA & $\mathrm{CL}$ & $582.4 \mathrm{e}$ & 0.661 & $864.9 \mathrm{~d}$ & 0.711 & 3 \\
\hline
\end{tabular}

${ }^{\mathrm{z}}$ Country from which the PI was originally collected.

${ }^{y}$ Citrullus groups: $\mathrm{P}=$ Praecitrullus fistulosus; $\mathrm{CL}=$ Citrullus lanatus; $\mathrm{CLL}=$ C. lanatus var. lanatus; $\mathrm{CLC}=C$. lanatus var. citroides; $\mathrm{CO}=C$. colocynthis.

${ }^{x}$ Mean ranks followed by the same letter are not significantly different $(P=0.05)$ based on nonparametric individual pairwise comparisons. There were 10 replications for each PI.

${ }^{\text {wE} E a c h ~ P I ~ h a d ~} 20$ single plant replication. Mean ranks followed by the same letter are not significantly different $(P=0.05)$ based on nonparametric individual pairwise comparisons. The RTE on six PIs over time for both greenhouse trails are presented in Figure 1.

'Percentage of plants that were rated less than 5 on the 1 to 9 scale when $97 \%$ of the 'Mickey Lee' control plants were dying or dead in the second trial.

Table 5. Test statistics for the effects of select U.S. plant introductions (PIs) and time on the severity of watermelon vine decline caused by squash vein yellowing virus in field trials conducted in 2006 and 2007.

\begin{tabular}{lccrr}
\hline & \multicolumn{4}{c}{ Analysis of variance-type statistic } \\
\cline { 2 - 5 } Effect & $d f_{N}$ & $d f_{D}$ & \multicolumn{1}{c}{$F$} & $P$ value \\
\hline Field trials & $2006^{\mathrm{y}}$ & & & \\
PI & 6.44 & 10.70 & 5.39 & 0.008 \\
Time (T) & 1.47 & $\infty$ & 146.90 & $<0.001$ \\
PI $\times$ T & 7.61 & $\infty$ & 2.59 & 0.009 \\
Field trials & 2007 & & & \\
PI & 5.21 & 16.76 & 6.70 & 0.001 \\
Time (T) & 1.61 & $\infty$ & 382.70 & $<0.001$ \\
PI $\times$ T & 8.27 & $\infty$ & 1.87 & 0.057 \\
\hline
\end{tabular}

${ }^{\mathrm{z}}$ Analysis of variance-type statistic was calculated using nonparametric methods as described by Shah and Madden (2004)

${ }^{y}$ In the field trials in 2006, there were three replications for each PI, and in 2007, there were four replications for each PI. Plants were rated on the 1 to 9 rating scale over a period of 12 weeks after planting.

$d f_{N}=$ numerator df; $d f_{D}=$ denominator $\mathrm{df}$.

disease compared with the susceptible controls in 2006 (Table 6); however, PI 381734 was not significantly different from the controls in 2007 (Table 7). PI 244018 (C. lanatus var. citroides) was very susceptible to SqVYV in 2006 and was not tested again in 2007.

In 2007 , all the fruits $(100 \%)$ of the susceptible control 'Mickey Lee' and 80\% fruits of 'Crimson Sweet' had typical symptoms of WVD. In comparison, the seven PIs had significantly less fruits with symptoms of WVD (Table 7). Almost none of the fruits of the C. colocynthis PI had symptoms of WVD. Although foliar symptoms on the $C$. lanatus var. citroides PI 500354 were not different from the controls, only $14 \%$ of the fruits exhibited symptoms of WVD.

\section{Discussion}

The core collection of the PIs can be considered as a representation of the entire watermelon PI collection available with USDA-ARS, PGRCU. We identified several PIs in the core collection that could be useful for developing a watermelon germplasm with resistance to SqVYV. From the initial screen, we selected PIs that had an average rating of less than 4.5 for further testing. None of the PIs tested in our study were completely immune to SqVYV. Resistance was generally manifested by a decrease in the rate of disease development relative to the commercial cultivars tested. The major findings of this screening are similar to what was found when screening for resistance to WMV (Gillaspie and Wright, 1993) and PRSV-W (Strange et al., 2002), in which immunity has not been found in watermelon, albeit resistance to these two viruses have been described. collection, we used single plants as replications because the intention was to quickly identify some potential sources of resistance that could be tested in the field against the newly described SqVYV. Single plant replications have been used in evaluating watermelon germplasm against powdery mildew (Davis et al., 2007), gummy stem blight (Gusmini et al., 2005), and PRSV-W (Strange et al., 2002); and it has been suggested that few replications may be adequate for rapid germplasm screening (Guner et al., 2002). We chose to evaluate young seedlings in the greenhouse studies because we had found in previous studies that young susceptible watermelon plants died very quickly when infected with SqVYV (Adkins et al., 2007). Moreover, field studies indicated that all growth stages of watermelon plants were highly susceptible to SqVYV (Adkins et al., 2006), and seedlings were much simpler to manipulate and much simpler to work with larger numbers of plants. Similarly, inoculations at the first true leaf stage were found to be the most appropriate for evaluating a wide
In the evaluation of the watermelon core variety of watermelon germplasms for resistance to PRSV-W (Guner et al., 2002; Strange et al., 2002). We also used a 1 to 9 ordinal disease rating scale to coincide with rating scales used by GRIN (http://www.ars-grin.gov) for watermelon. Moreover, the rating scale made for quick assessment because quantification is difficult as a result of the variety of symptoms expressed by virusinfected plants.

All the four C. lanatus var. lanatus PIs that were selected from the core collection for further evaluation were collected originally from southern regions of the African continent and these four reduced the disease progress significantly compared with the susceptible controls. Thus, it may be worthwhile to evaluate all the $C$. lanatus and $C$. lanatus var. lanatus PIs collected from this region for tolerance to SqVYV because it is relatively easy to cross $C$. lanatus var. lanatus PI with commercial cultivars. However, it is our intention to evaluate the entire watermelon PI collection, which consists of over 1700 PIs, in the near future to identify more diverse sources of resistance. Although severe symptoms were observed on the foliage of the C. lanatus var. citroides PI 500354 in 2007 , only $14 \%$ of the fruits had symptoms of WVD. Furthermore, PI 500354 had significantly less disease than the controls in 2006 field trials, the initial core evaluation trial, and the two greenhouse trials, indicating that useful selections to develop resistant germplasm can be made from this PI.

In both our greenhouse trials, variability in levels of resistance was detected among individual plants within most of the PIs evaluated and at the last rating, many of the plants within PIs were dead. Similar results were observed in greenhouse trials on watermelon PIs inoculated with PRSV-W, in which all PIs infected with the virus eventually died (Strange et al., 2002). The variability in reaction within watermelon and other cucurbit PIs to diseases and pests is well documented (Boyhan et al., 1992; Davis et al., 2007; Gillaspie and Wright, 1993; Guner et al., 2002; Gusmini et al., 2005; Kousik et al., 2007c; Strange et al., 2002). One of the reasons suggested for this variability is that most of the accessions in the collection have been increased by open pollination at some point, thus providing the chance for crosspollination of some of the accessions (Gillaspie and Wright, 1993; Strange et al., 2002). In addition, these accessions were originally collected in the open from various regions of the world and may have been crosspollinated before collection. This variability makes it necessary to develop resistant germplasm lines by careful selection and screening of the existing PIs. For example in greenhouse Trial 2 (Table 4), when $97 \%$ of the susceptible 'Mickey Lee' control plants were dying or dead (rated greater than 8), over half $(54 \%)$ of the plants of PI 386015 and $32 \%$ of PI 392291 were rated less than 5 and were still alive (Table 4) indicating much slower progress of the disease. These plants also produced fruits that could be harvested 
Table 6. Mean rank and relative treatment effect (RTE) for the effects of select U.S. plant introductions (PIs) on the severity of watermelon vine decline caused by squash vein yellowing virus in field trials conducted in Fall 2006, Immokalee, FL.

\begin{tabular}{|c|c|c|c|c|c|c|c|}
\hline \multirow[b]{2}{*}{ PI } & \multirow[b]{2}{*}{ Country $^{z}$} & \multirow{2}{*}{$\begin{array}{c}\text { Citrullus } \\
\text { group }^{\mathrm{y}}\end{array}$} & \multicolumn{3}{|c|}{ Mean rank on ${ }^{\mathrm{x}}$} & \multirow{2}{*}{$\begin{array}{l}\text { Overall mean } \\
\text { rank }^{\mathrm{w}}\end{array}$} & \multirow[b]{2}{*}{ RTE } \\
\hline & & & 30 Oct. & 20 Nov. & 4 Dec. & & \\
\hline$\overline{\text { PI } 386015}$ & Iran & $\mathrm{CO}$ & 12 & 39 & 57 & $36.0 \mathrm{ab}^{\mathrm{v}}$ & 0.382 \\
\hline PI 386024 & Iran & $\mathrm{CO}$ & 6 & 42 & 55 & $34.0 \mathrm{a}$ & 0.360 \\
\hline PI 482266 & Zimbabwe & CLL & 17 & 34 & 72 & $41.0 \mathrm{~b}$ & 0.435 \\
\hline PI 392291 & Kenya & CLL & 25 & 32 & 72 & $43.0 \mathrm{~b}$ & 0.457 \\
\hline PI 381734 & India & CLL & 16 & 41 & 72 & $43.0 \mathrm{~b}$ & 0.457 \\
\hline PI 299378 & South Africa & CLC & 20 & 65 & 72 & $52.3 \mathrm{bc}$ & 0.557 \\
\hline PI 244018 & South Africa & CLC & 18 & 72 & 72 & $54.1 \mathrm{c}$ & 0.576 \\
\hline PI 295850 & South Africa & CLC & 23 & 72 & 72 & $55.7 \mathrm{c}$ & 0.594 \\
\hline PI 500354 & Zambia & CLC & 2 & 19 & 56 & $25.8 \mathrm{a}$ & 0.272 \\
\hline Crimson Sweet & USA & $\mathrm{CL}$ & 43 & 72 & 72 & $62.3 \mathrm{~cd}$ & 0.665 \\
\hline Mickey Lee & USA & $\mathrm{CL}$ & 52 & 72 & 72 & $62.5 \mathrm{~d}$ & 0.699 \\
\hline
\end{tabular}

${ }^{\mathrm{z}}$ Country from which the PI was originally collected.

${ }^{\text {y } C i t r u l l u s}$ groups: $\mathrm{CL}=C$. lanatus; $\mathrm{CLL}=C$. lanatus var. lanatus; $\mathrm{CLC}=C$. lanatus var. citroides; $\mathrm{CO}=$ C. colocynthis.

${ }^{\mathrm{x}}$ Mean rank for each PI on the day ratings were made.

${ }^{\mathrm{w}}$ Overall mean rank based on ranks for all the ratings taken during the season.

${ }^{v}$ Overall mean ranks followed by the same letter are not significantly different $(P=0.05)$ based on nonparametric individual pairwise comparisons.

Table 7. Mean rank and relative treatment effect (RTE) for the effects of select U.S. plant introductions (PIs) on the severity of watermelon vine decline (WVD) caused by squash vein yellowing virus and percent of fruits with symptoms of WVD in field trials conducted in Fall 2007, Immokalee, FL.

\begin{tabular}{|c|c|c|c|c|c|c|c|c|}
\hline \multirow[b]{2}{*}{ PI } & \multirow[b]{2}{*}{ Country ${ }^{z}$} & \multirow{2}{*}{$\begin{array}{l}\text { Citrullus } \\
\text { group }^{\mathrm{y}}\end{array}$} & \multicolumn{3}{|c|}{ Mean rank on ${ }^{\mathrm{x}}$} & \multirow{2}{*}{$\begin{array}{c}\text { Overall } \\
\text { mean rank }{ }^{\mathrm{w}}\end{array}$} & \multirow[b]{2}{*}{ RTE } & \multirow{2}{*}{$\begin{array}{c}\text { Fruit } \\
\text { WVD }(\%)^{\mathrm{u}}\end{array}$} \\
\hline & & & 18 Oct. & 27 Nov. & $10 \mathrm{Dec}$. & & & \\
\hline$\overline{\text { PI } 386015}$ & Iran & $\mathrm{CO}$ & 43 & 111 & 122 & $72.3 \mathrm{a}^{\mathrm{v}}$ & 0.399 & $0.0 \mathrm{~d}$ \\
\hline PI 386024 & Iran & $\mathrm{CO}$ & 43 & 118 & 133 & $75.8 \mathrm{ab}$ & 0.419 & $1.9 \mathrm{~d}$ \\
\hline PI 482266 & Zimbabwe & CLL & 56 & 128 & 138 & $84.1 \mathrm{bc}$ & 0.464 & $36.9 \mathrm{c}$ \\
\hline PI 392291 & Kenya & CLL & 43 & 143 & 155 & $85.4 \mathrm{c}$ & 0.472 & $19.5 \mathrm{~cd}$ \\
\hline PI 459074 & Botswana & CLL & 70 & 137 & 155 & $95.0 \mathrm{~cd}$ & 0.525 & $22.5 \mathrm{~cd}$ \\
\hline PI 381734 & India & CLL & 70 & 141 & 163 & $96.4 \mathrm{~cd}$ & 0.533 & $39.2 \mathrm{c}$ \\
\hline PI 500354 & Zambia & CLC & 86 & 133 & 170 & $100.8 \mathrm{~d}$ & 0.557 & $14.2 \mathrm{~cd}$ \\
\hline Crimson Sweet & USA & CL & 87 & 145 & 161 & $98.0 \mathrm{~d}$ & 0.542 & $80.6 \mathrm{~b}$ \\
\hline Mickey Lee & USA & $\mathrm{CL}$ & 86 & 170 & 177 & $106.8 \mathrm{~d}$ & 0.590 & $100.0 \mathrm{a}$ \\
\hline
\end{tabular}

${ }^{\mathrm{z}}$ Country from which the PI was originally collected.

${ }^{y}$ Citrullus groups: $\mathrm{CL}=C$. lanatus; $\mathrm{CLL}=C$. lanatus var. lanatus; $\mathrm{CLC}=C$. lanatus var. citroides; $\mathrm{CO}=$ C. colocynthis.

${ }^{\mathrm{x}}$ Mean rank for each PI on the day ratings were made. All ranks on the first rating on 27 Sept. were not significantly different and were $=43$.

wOverall mean rank based on ranks for all the ratings taken during the season.

${ }^{v}$ Overall mean ranks followed by the same letter are not significantly different $(P=0.05)$ based on nonparametric individual pairwise comparisons.

uPercent of fruits showing watermelon vine decline symptoms for each PI recorded on 10 Dec. 2007. Mean percentages followed by the same letter are not significantly different $(P=0.05)$.

for seeds. We have made selections of the most resistant plants within these PIs to develop resistant germplasm. We could not test some of the PIs in all the trials because of limited availability of seeds.

The Praecitrullus fistulosus PI 381749 from India was the most tolerant in both greenhouse trials. However, it will be difficult to use this resistance using traditional breeding methods because the genetic distance between the commercially cultivated watermelon and $P$. fistulosus is fairly large (Dane and Lang, 2004; Levi et al., 2005), such that crosses between $P$. fistulosus and Citrullus sp. are very difficult to make (Levi et al., 2005). However, this information on some resistance in PI 381749 to SqVYV may be useful to breeders in places where fruits of $P$. fistulosus commonly called 'Tinda' are used for human consumption.

The two Citrullus colocynthis desert watermelon PIs from Iran (PI 386015 and PI 386024) had significantly less disease compared with the controls in all the trials. Previously, several C. colocynthis PIs collected from Iran were found to be resistant to ZYMV (Boyhan et al., 1992). However, resistance to one virus may not always translate into resistance to others; for example, in 2006, we included PI 244018 in our field trials because it was reported to be resistant to WMV (Gillaspie and Wright, 1993) and PRSV-W (Strange et al., 2002). However, we found PI 244018 to be very susceptible to SqVYV. Interestingly, PI 386015 and several other $C$. colocynthis PIs in the collection are tolerant to whiteflies (Simmons and Levi, 2002) and broad mites (Kousik et al., 2007c) and PI 386024 has also been shown to posses some resistance to WMV (Gillaspie and Wright, 1993) and PI 386015 to powdery mildew (Davis et al., 2007). Apart from tolerance to whiteflies and broad mites, most of the $C$. colocynthis PIs also have resistance to spider mites (Lopez et al., 2005).
A combination of resistance to whiteflies and the virus in a plant offers an interesting management strategy for many crops. Several sources of resistance to whiteflies have been identified in wild-type watermelon and it has been suggested that this resistance may be the result of the higher density of trichomes compared with most other Citrullus spp. (Simmons and Levi, 2002). However, horticulturally acceptable whitefly-resistant watermelon cultivars have not yet been developed. It would be interesting to evaluate the SqVYV-resistant PI identified in this study for resistance to whiteflies. In our greenhouse studies, the two SqVYV-resistant C. colocynthis PIs were mechanically inoculated, thus potentially overcoming any physical barriers that might offer resistance to the whiteflies. Although the C. colocynthis PI 386015 and PI 386024 are known to possess some resistance to whiteflies (Simmons and Levi, 2002), based on our study, it is possible that the whiteflies can still transmit the virus. Furthermore, our studies also indicate that the genes conferring tolerance to whiteflies and to SqVYV may be different. The two C. colocynthis can be useful sources of resistance for developing SqVYV-tolerant germplasm by crossing them with SqVYVtolerant $C$. lanatus var. citroides or $C$. lanatus var. lanatus PIs. Although it is somewhat difficult to make a cross of $C$. colocynthis with the cultivated watermelon, successful crosses have been made (Levi et al., 2002) and germplasm released (Levi et al., 2006).

In summary, immunity to SqVYV was not detected in any of the PIs evaluated. Similarly, only partial resistance to the whiteflytransmitted CVYV was detected in land races of cucumbers (Pico et al., 2003). This partial resistance could be transferred to F1 hybrid by crossing with a highly susceptible cucumber (Pico et al., 2005). In our studies, we did detect varying levels of resistance in several C. lanatus var. lanatus PIs (PI 482266, PI 392292, and PI 459074) and C. lanatus var. citroides PI (PI 500354) that can be easily crossed with the cultivated watermelon $(C$. lanatus). Our studies did indicate that these PIs could significantly slow down disease development over time compared with the susceptible cultivars. However, our study also indicated that under extreme circumstances, the resistance offered by some of the genes in these PIs may not be enough to manage the disease. Therefore, even when some of these resistant genes are moved into commercial cultivars, an integrated approach, including the use of reflective mulch, application of pesticides to control whitefly populations, and cucurbit weed/volunteer control, will be needed to manage WVD.

\section{Literature Cited}

Adkins, S., S.E. Webb, D. Achor, C.S. Kousik, P.D. Roberts, and C.A. Baker. 2006. Squash vein yellowing virus, a novel Ipomovirus isolated from squash and watermelon in Florida. Proc. 4th International Bemisia workshop; 3-6 December 2006. p. 59. 
Adkins, S., S.E. Webb, D. Achor, P.D. Roberts, and C.A. Baker. 2007. Identification and characterization of a novel whitefly-transmitted member of the family Potyviridae isolated from cucurbits in Florida. Phytopathology 97:145-154.

Adkins, S., S.E. Webb, C.A. Baker, and C.S. Kousik. 2008. Squash vein yellowing virus detection using nested polymerase chain reaction demonstrates that the cucurbit weed Momordica charantia is a reservoir host. Plant Dis. 92:1119-1123.

Akritas, M.G. and E. Brunner. 1997. A unified approach to rank tests for mixed models. J. Stat. Plan. Infer. 61:249-277.

Al-Musa, A.M., S.J. Qusus, and A.N. Mansour. 1985. Cucumber vein yellowing virus on cucumber in Jordan. Plant Dis. 69:361.

Boyhan, G., J.D. Norton, B.J. Jacobsen, and B.R. Abrahams. 1992. Evaluation of watermelon and related germ plasm for resistance to zucchini yellow mosaic virus. Plant Dis. 76:251-252.

Brunner, E., S. Domhof, and F. Langer. 2002. Nonparametric analysis of longitudinal data in factorial experiments. John Wiley \& Sons, New York, NY.

Cuadrado, I.M., D. Janssen, L. Velasco, L. Ruiz, and E. Segundo. 2001. First report of cucumber vein yellowing virus in Spain. Plant Dis. 85:336.

Dane, F. and P. Lang. 2004. Sequence variation at cpDNA regions of watermelon and related wild species: Implications for the evolution of Citrullus haplotypes. Amer. J. Bot. 91:1922-1929.

Davis, A.R., A. Levi, A. Tetteh, A Wehner, T.C. Wehner, V. Russo, and M. Pitrat. 2007. Evaluation of watermelon and related species for resistance to race $1 \mathrm{~W}$ powdery mildew. $\mathrm{J}$. Amer. Soc. Hort. Sci. 132:790-795.

Dennehy, T.J., B.A. DeGain, V.S. Harpold, J.K. Brown, S. Morin, J.A. Fabrick, and R.L. Nichols. 2005. New challenges to management of whitefly resistance to insecticides in Arizona. Univ. Ariz., College of Agr., Veg. Rpt. 1 Sept. 2009. <http:// mrec.ifas.ufl.edu/lso/DOCUMENTS/Dennehy\% 20et\%20al\%2005\%20WF\%20Report-Extension. pdf?.

Egel, D.S. and S. Adkins. 2007. Squash vein yellowing virus identified in watermelon (Citrullus lanatus) in Indiana. Plant Dis. 91:1056.

Gillaspie, A.G. and J.M. Wright. 1993. Evaluation of Citrullus sp. germ plasm for resistance to watermelon mosaic virus 2. Plant Dis. 77:352-354.

Guner, N., B.E. Strange, T.C. Wehner, and Z. PesicVanEsbroeck. 2002. Methods for screening watermelon for resistance to papaya ringspot virus type-W. Sci. Hort. 94:297-307.

Gusmini, G., R. Song, and T.C. Wehner. 2005. New sources of resistance to gummy stem blight in watermelon. Crop Sci. 45:582-588.

Huber, M. 2006. Taking vital vines. Citrus and Vegetable Magazine 70:22-24.

Kousik, C.S., S. Adkins, and P.D. Roberts. 2007a. Evaluation of select USDA watermelon plant introductions (PI) for tolerance to watermelon vine decline, 2006. Plant Disease Management Reports. 1:V012.

Kousik, C.S., S. Adkins, and P.D. Roberts. 2007 b. Potential sources of resistance in watermelon plant introductions (PI) to watermelon vine decline in Florida. Phytopathology 97:S59 (abstr.).

Kousik, C.S., B.M. Shepard, R. Hassell, A. Levi, and A.M. Simmons. 2007c. Potential sources of resistance to broad mites (Polyphagotarsonemus latus) in watermelon germplasm. HortScience 42:1539-1544.

Kousik, C.S., S.T. Adkins, W.W. Turechek, and P.D. Roberts. 2008. Use of reflective plastic mulch and insecticide sprays to manage viral watermelon vine decline in Florida, 2007. Plant Disease Management Reports. 2:V169.

Levi, A., C.E. Thomas, T. Joobeur, X. Zhang, and A. Davis. 2002. A genetic linkage map for watermelon derived from a test cross population: (Citrullus lanatus var. citroides $\times C$. lanatus var. lanatus $) \times$ Citrullus colocynthis. Theor. Appl. Genet. 105:555-563.

Levi, A., C.E. Thomas, A.M. Simmons, and J.A. Thies. 2005. Analysis based on RAPD and ISSR markers reveals closer similarities among Citrullus and Cucumis species than with Praecitrullus fistulosus (stocks) Pangalo. Genet. Resources Crop Evol. 52:465-472.

Levi, A., C.E. Thomas, J.A. Thies, A.M. Simmons, K.S. Ling, H.F. Harrison, R. Hassell, and A.P. Keinath. 2006. Novel watermelon breeding lines containing chloroplast and mitochondrial genomes derived from the desert species Citrullus colocynthis. HortScience 41:463464.

Lopez, R., A. Levi, B.M. Shepard, A.M. Simmons, and D. Jackson. 2005. Sources of resistance to two spotted spider mite (Acari: Tetranychidae) in Citrullus spp. HortScience 40:1661-1663.

Marco, C.F., M.A. Aranda, T. Montoro, and M.L. Gómez-Guillamón. 2003. Evaluation of several accessions and wild relatives of Cucumis melo against cucumber vein yellowing virus (CVYV). Cucurbit Genetics Cooperative Report 26:7-8.

Olson, S.M., E.H. Simonne, W.M. Stall, P.D. Roberts, S.E. Webb, T.G. Taylory, S.A. Smith, and J.H. Freeman. 2007. Cucurbit production in Florida, Chapter 27, p. 201-250. In: Olson, S.M. and E. Simonne (eds.). Vegetable Production Handbook for Florida.

Pico, B., A. Sifres, and F. Nuez. 2005. Quantitative detection of cucumber vein yellowing virus in susceptible and partially resistant plants using real-time PCR. J. Virol. Methods 128:14-20.

Pico, B., C. Villar, and F. Nuez. 2003. Screening Cucumis sativus landraces for resistance to cucumber vein yellowing virus. Plant Breed. 122:426-430.

Roberts, P., R. Muchovej, R. Urs, D. Achor, C. Baker, B. Bruton, and S. Adkins. 2005. Investigation into a mature watermelon vine decline and fruit rot. Phytopathology 95(suppl.):S89 (abstr.).

Schuster, D.J., R. Mann, and P.R. Gilreath. 2006. Whitefly resistance update and proposed mandated burn down rule, p. 24-28. In: Gilreath, P. and K. Cushman (eds.). 2006 Fla. Tomato Institute Proc., Univ. Fla., PRO 523.

Schuster, D.J., P.A. Stansly, J.E. Polston, P.R. Gilreath, and G.E. McAvoy. 2007. Management of whiteflies, whitefly-vectored plant virus, and insecticide resistance for vegetable production in southern Florida. IFAS Extension Publication ENY-735. 1 Sept. 2008. <http:// edis.ifas.ufl.edu/pdffiles/IN/IN69500.pdf>.

Shah, D.A. and L.V. Madden. 2004. Nonparametric analysis of ordinal data in designed factorial experiments. Phytopathology 94:33-43.

Simmons, A.M. and A. Levi. 2002. Sources of whitefly (Homoptera: Aleyrodidae) resistance in Citrullus for the improvement of cultivated watermelon. HortScience 37:581-584.

Strange, B.E., N. Guner, Z. Pesic-VanEsbroeck, and T.C. Wehner. 2002. Screening the watermelon germplasm collection for resistance to papaya ringspot virus type-W. Crop Sci. 42:1324-1330.

Xu, Y., D. Kang, Z. Shi, H. Shen, and T.C. Wehner. 2004. Inheritance of resistance to Zucchini yellow mosaic virus and watermelon mosaic virus in watermelon. J. Hered. 95:498-502.

Yilmaz, M.A., M. Ozaslan, and D. Ozaslan. 1989. Cucumber vein yellowing virus in Cucurbitaceae in Turkey. Plant Dis. 73:610. 